\title{
Human Resource Management Strategy as a Small Business Competitive Advantage Tool
}

\author{
Jan $\operatorname{Urban}^{1, *}$ \\ ${ }^{1}$ Institute of Technology and Business, Faculty of Corporate Strategy, Okružní 517/10, 37001 České Budějovice, Czech Republic
}

\begin{abstract}
The goal of a company's HR management (HRM) strategy is to define its medium-term objectives in HRM and development as well as to specify the main management tools needed for their achievement. The HRM goals set by this strategy should be linked to the company's strategic business goals and respond in advance to its medium term HRM requirements dictated by both internal and external factors. Corresponding HRM measures and/or policies should be effective in terms of achieving HRM objectives, as well as efficient in terms of their costs and benefits relations. The purpose of this paper based on a qualitative analysis of interviews with small business owners focused on the importance of their HRM strategy for the competitive advantage of their emerging companies, as well as on relevant secondary sources, is to outline a particular methodology and the main characteristics of successful HRM strategies. The main attention is drawn to the linkage of the HRM strategy to the overall companies' business strategies as well as their appropriate contents and structure.
\end{abstract}

Keywords: business strategy; HR management strategy; HR strategy goals and tools; HRM SWOT analysis

\section{Introduction}

A properly conceived HRM strategy allows a timely response to the future HRM needs of companies [1,2]. Such a response, leaning usually on a companies' HRM SWOT analysis [3,4], can support the strengths of their human resources as well as the strengths of their HRM policy measures, eliminate their weaknesses, face in advance the potential external HRM threats and respond to new HRM external opportunities [5].

The task of the HRM strategy is therefore to clearly define a company's medium-term HRM goals focusing, among other things, on HR development, and to set appropriate tools and measures to achieve them, primarily those whose impact will take some time. The HRM strategy is especially important when HRM can become an important tool for creating the company's competitive advantage [6]. This quite often concerns small businesses.

An important part of the HRM strategy includes a plan of costs and benefits associated with alternative HRM measures $[3,7]$. A common practical weakness of HR strategies, on the other hand, is their detachment from the overall business strategy and their rather formal and/or vague nature as well their missing or insufficiently specific measures to achieve their HR goals [2]. In these cases, the HR strategy lacks its efficiency and effectiveness [1,8].

The aim of the paper is to point out the importance and requirements of an effective and efficient HRM strategy and to establish an overall as well as sufficiently detailed methodology on which creating the effective and efficient HRM strategy is based. The main focus is related to the HRM strategy of emerging and small businesses as a tool of their competitive advantage.

\section{Methodology}

Methodologically, the paper is based on a qualitatively oriented, multiple-case study. Its two mutually interrelated research questions were "What type of HRM strategies characterize successful emerging and/or small-businesses and which HR strategic management skills do small-business owners need to succeed/survive in their business?"

Answering these questions was based on the experience and common views of entrepreneurs who successfully survived five years in business. The sample comprised 16 small business owners residing in Central Bohemia and operating small retail shops, personal services and professional service shops and outlets who sustained their business beyond 5 years, employed 10 to 50 employees and mana managed a growing and viable/profitable business entity.

\footnotetext{
* Corresponding author: 21537@ mail.vstecb.cz
} 
Data gathering was based on face-to-face semi-structured interviews providing data for answering the above research questions. Data saturation occurred when no new or relevant themes or supporting information emerged during the data collection process (in relation to the methodology suggested by $[9,10]$ ).

The main questions presented in these interviews were to find out whether or not the emerging businesses had an HRM strategy, what were the main goals and measures of their HRM strategy, what methods were used in conceiving their HRM strategy, which point, in retrospect, would the entrepreneurs put more stress on when conceiving their HRM strategy, what, in their view, were the main points on which their business, in terms of their HRM strategy, was based, what were the main differences, in their understanding, of their HRM strategy compared with their less successful competitors, what were the main HRM skills they lacked when they started their business, what main HRM skills they gained when managing their business, and if their HRM strategy changed during and after the first years in business.

At the same time, to confront the results gained form the structured interviews, these results (entrepreneurs' opinions) were compared with the results and recommendations of secondary sources $[11,12]$ dealing with an HRM strategy creation $[13,14]$ and implementation [15] in general and in small companies [16]. Regarding, however, the questions raised in this paper, specifically the question of entrepreneurial skills and steps for generating a successful HRM strategy of emerging and/or small companies, such sources are relatively scarce [16]. Most of the recommendations in this paper, if not stated otherwise (by a reference to literature), are thus original recommendations which raised from the results gained.

An important part of the method used was a distinction made between an effective and an efficient HRM strategy. This issue was raised by the interviewed entrepreneurs and can also be found in relevant literature [15,16]. Those HRM strategies that focus on HR goals and measures supporting competitiveness (current or future competitive advantages of companies are seen as effective HR strategies, whereas those trying to identify HR policies, which at the same time analyse costs and benefits of alternative HR measures financially, are considered as efficient. Evidently, efficient strategies are crucially important for start-ups and small companies [16]

\section{Results and Discussion}

According to the interviews, the success of a newly established company depends on its ability to conceive a relevant and realistic HRM strategy. The main characteristics of this strategy contributing to the company's success, especially in early stages of business development, can be summarized as follows.

(1) The starting point of a successful HRM strategy involves its medium-term business goals. Linkage to the company's strategy is a key prerequisite for a properly defined HRM strategy; on the contrary, its detachment from the company's overall strategy is one of its most serious weaknesses.

(2) An HRM strategy should set out key HR assumptions on which the fulfilment of the company's objectives will be based, identify corresponding medium-term HRM objectives (sorted usually by individual HR processes) and propose HRM tools or measures (" HR policies ") leading to their achievement.

(3) A successful HRM strategy structure should follow the above mentioned guidelines.

\subsection{Structure of HR strategy}

The basic scheme of HRM, corresponding usually to the main steps of its creation, consists of five main areas [15], namely:

- a long-term HR vision of the company containing its basic values or credo. This part of the HR strategy is primarily of motivational and communication importance,

- medium-term HR prerequisites necessary for the fulfilment of the company's strategic business goals,

- characteristics (or a critical analysis) of the current HR status of the organization, its strengths and weaknesses and development trends. This step is used to assess which of the HR prerequisites for successful future development the organization should focus on,

- $\quad$ specific HRM goals of the company and measures, HR policies, or their variants, on the basis of which these goals will be achieved. This set of objectives should also include ways to evaluate them,

- a tactical plan, setting out sub-tasks, their deadlines and responsibilities for their fulfilment. The main HR goals are assigned to individual departments or persons, and the resources that will be released to achieve the goals and the way in which the fulfilment of the goals will be controlled are determined.

The core of the HRM strategy includes the second, the third and the fourth points, which can be seen as an HRM strategic plan. It is also the starting point for continuously updated annual staffing plans.

The strategic HRM plan of the organization should ideally [17] be divided into five to six areas, corresponding to the main sections of HRM. They consist of a medium-term plan of HR costs, new personnel need and recruitment 
requirements (or, as the case of may be, dismissal of employees), motivation and remuneration, skills development, performance management (setting personal performance goals and their regular evaluation), or a plan of corporate values and corporate culture [18].

\subsection{Medium-term HRM assumptions of corporate goals}

The starting point for the medium-term HRM strategy encompasses the HR assumptions/prerequisites necessary for the fulfilment of the company's strategic business goals and/or its future market success. The basic tool for their definition is the organization's strategic SWOT analysis [17] identifying the main factors of future competitive advantages of the company. Examples of these can involve, for example, high quality and reliability of production, low price, an ability to adopt rapid technological or product innovations, an individual/personal approach to customers, etc.

In order to correctly determine the HRM prerequisites for the company's successful future development, the entrepreneurs that participated in the interviews mentioned the necessity to ask questions such as: "What future HRM prerequisites are crucial for the company's business strategy", "What HRM requirements will be needed to achieve its competitive advantages?" or "What future employee skills and motivation as well as their management and organization methods will be necessary to implement the corporate strategy goals?

More specifically, the medium-term HR assumptions of the company should relate to all basic HRM areas, i.e. the number of employees, their structure, skills and motivation, their costs, how these employees will need to be managed (for example, what powers will need to be delegated), what organizational structure will be most suitable for the company, what elements of corporate culture will be relied on, etc.

Determining the HR prerequisites that will be needed to fulfil the corporate strategy is, according to most of the entrepreneurs questioned, not only the initial, but also the most important part of the HRM strategy. It is therefore important that the people who create the HRM strategy (if it is not created by the entrepreneurs themselves) understand the critical factors of the future success of the company well.

\subsection{Differences in HRM assumptions of different business strategies}

HRM assumptions of different business strategies can differ significantly and therefore cannot be mechanically taken over from other companies. For example, HRM assumptions corresponding to the strategy of the lowest possible costs and/or prices will be significantly different from the assumptions required by strategies based on an individual approach to customers or rapid innovation capacity [17].

This may be illustrated by specific examples which the research, or enquiry, revealed. For an organization whose competitiveness is based on technological innovations and their rapid introduction to the market, i.e. a company operating in the field of new technologies, the main HRM prerequisites include the ability to acquire, retain and use top talent and ensure their further development.

In a company of this type, the long-term need to acquire and retain these employees may take precedence over the (short-term) effort to save on their costs. Financing their development should therefore not decrease even in periods of reducing business costs. Another HRM assumption may relate to their remuneration: the basic and starting salaries of individual employees working in equally qualified positions in these conditions may differ significantly depending on their personal abilities or contribution to the creation and introduction of new products.

On the other hand, HRM prerequisites of a company with a decisive emphasis on reducing and controlling operating costs (for example, companies facing strong price competition) will be significantly different. The determination of basic and starting salaries should be based primarily on the requirements of internal equality in remuneration and group motivation. The reason is that teamwork and group performance are usually more important here than the individual contribution or performance of each employee. Differences in the level of basic salaries therefore lack economic justification (individuals with a higher price do not pay) and may also be a threat to teamwork [8].

\subsection{Analysis of the current HR status}

The second basic step in creating an HRM strategy is to compare the HR prerequisites necessary to fulfil the company's business strategy with the current or near future HRM situation of the company and/or its development tendencies. The purpose of this step is to analyse the main weaknesses or limitations of the current HRM situation of the company, especially those that need to be addressed well in advance [19].

This analysis should, according to the successful entrepreneurs surveyed, ask questions such as: "How do our current HR situation and development meet our future HR as well as HRM requirements and what are its main weaknesses?", "What limitations in terms of future requirements are related the abilities of our employees or the methods they develop?", "From the viewpoint of important HRM preconditions for future development, what limitations does our way of managing, motivating or rewarding employees bring?", "What limitations can our organization, corporate culture, etc. place?". 
Answers to these questions reveal HR weaknesses/bottlenecks in the given company (both in terms of its current state or development trends), which the HRM strategy should try to eliminate.

\subsection{HR goals and measures}

The third main step in creating an HRM strategy is setting medium-term HRM goals. They are designed to overcome the existing HRM weaknesses and respond in a timely manner to adverse external HRM trends concerning the organization. The measures necessary to achieve these goals should correspond to them.

Particular HR goals, according to the successful entrepreneurs surveyed, should be as specific as possible: if possible, they should be set in the form of specific values of HR indicators, or other ways in which the achievement of the set goals can be monitored. The specificity of the objectives and the proposed measures as well as the method of their evaluation is usually the most important prerequisite for this step, as pointed out by the successful entrepreneurs.

For example, if the identified weakness involves increased HR costs associated with a higher turnover of new employees, the HR strategy may include a specific HRM objective "to reduce the turnover rate in the first year of work to 5\%" and indicate measures to achieve it. Other examples include improving employee selection, their adaptation, etc.

\subsection{Variant (alternative) HRM measures}

An important part of this step is to consider and assess alternative tools or measures that will enable to eliminate the identified HRM weaknesses. An example one of the entrepreneurs stated is the company's effort to respond to employee dissatisfaction with the way they are evaluated (its subjectively perceived injustice), which may lead to a proposal to train managers in the impartial evaluation of subordinates. However, managers may be very aware of the bias of their evaluation, but may not be sufficiently motivated to eliminate it. Therefore, their training is not an adequate solution.

Variant HR tools or measures should be assessed both in terms of their expected benefits and their (direct and indirect) costs. As in other areas of company management, the evaluation of alternative procedures should be based on an analysis of the expected impact of the proposed measures on the costs and revenues of the company, i.e. cost-benefit analysis, successful entrepreneurs suggest.

An example could be a measure consisting in adjusting the method of evaluating candidates in a selection procedure. The impact of this measure on costs may be either a reduction or an increase in the direct costs of the selection process (due to a reduction or an extension of its existing activities, a shortening or a lengthening of its duration, etc.) or an impact on its indirect costs (due to a higher or a lower probability of a wrong HR decision).

Part of this step of the HRM strategy should be the identification of factors that affect the probability of success or failure of the proposed measures. Factors that increase the likelihood of success of a proposed measure, according to the successful entrepreneurs surveyed, may include, for example, employees requiring similar measures, the measure facilitating the work of managers, having influential supporters, or similar measures having been successfully implemented in the past. On the contrary, risk factors may include the fact that managers or employees were not involved in related training, the company does not have sufficient know-how for implementing the measure or its time schedule is not realistic, etc.

\subsection{Evaluation of HR measures implemented}

The way in which results of the proposed measures will be evaluated must, according to the successful entrepreneurs surveyed, be determined in advance. In simpler cases, this assessment can be based on way how ta particular proposed measure, such as a change in the way of how higher performance is remunerated, has reflected in changes in employee behaviour or satisfaction. In the case of more complex or costly measures, their impact assessment should be based on performance indicators. Examples may include savings in HR costs, increased productivity, reduced scrap, etc. Evaluations of this type may be considered, for example, when assessing the results of a longer-term program aimed at increasing employee motivation. This experience of the successful entrepreneurs surveyed corresponds to certain recommendation in literature [20].

For long-term measures important for achieving the company's strategic HR goals (for example, increasing customer satisfaction, reducing absenteeism or turnover, etc.), evaluating of HR measures should also be based on estimating their financial return, using ROI, i.e. return on investment indicator. This requires to fully define the expected costs and benefits of the planned measure in financial terms and comparing them with one another [20].

In addition to setting out the ways in which the success of the proposed measures will be assessed, this section of the HRM strategy should also include setting deadlines for the main strategic objectives to be critically reviewed in order to assess their relevance [21]. 


\section{Conclusion}

The importance of any HRM strategy resides in the fact that it allows to respond correctly and well in advance to future, both internal and external, HR and HRM requirements of the company.

The majority of surveys' participants claimed that the main HRM challenges for their business development concerned HR related issues, especially "a high rate of employee turnover and/or hiring the right people", typical issues demanding an appropriate strategy approach. At the same time, most of the respondents noted the challenge of keeping staff motivated and happy, as well as keeping an open dialog and clear communications of expectations which they regarded as critical. Though already offering motivational rewards, most companies stressed the necessity of more effective and efficient remuneration strategy. In a similar context, a lot of them expressed a strategic need to improve their interview process to make better hiring decisions.

A large number of the participants stated that, similar to any successful business strategy, the related HRM strategy requires an ability to critically analyse the current HR situation of the organization, both in terms of staff quality and its management and organization, and an ability to bring, if necessary, new or alternative solutions.

Contrary to some simple views, formulating the company's HRM strategy in their opinion means not only determining what the number of its employees should be in the future or what their qualification structure should be, but also how they should be managed, motivated and rewarded, what new skills the company should develop, what methods of development should be used, how it might be necessary to adapt the company's organizational structure, redefine some jobs, or which measures should be taken to develop the company culture..

The main and, as the author believes, original findings of this paper can be summarized in the following sentences. The main conclusion, which the successful entrepreneurs approached in the survey agreed on, is related to the quality of the HRM strategy, i.e. its effectiveness and cost-efficiency, depending on its connection to the business strategy. The precondition for this is the correct determination of HRM assumptions needed for keeping and further development of current and future competitive advantages of the company, concretization of HRM goals as well as a clear and sufficiently specific determination of longer-term measures or HRM policies enabling their fulfilment. The cost-effectiveness of a particular HRM strategy, they claimed, usually also presupposes an assessment of alternative HRM measures and policies, including an estimate of their costs and expected benefits.

Recommendations for further research include focusing on different sizes of small business in different industries and varying geographical locations. Future researchers should also consider studying the issue the extant research has not effectively explained, i.e. why differences in employee-based resources persist across firms that have adopted the same firm-level HR strategy. Moreover, focusing on each of the specific parts of HRM strategy identified within this paper would provide more detailed areas for additional research.

\section{References}

1. M. Armstrong, D. Brown. Strategic Human Resource Management: Back to the future? Brighton: Institute for Employment Studies (2019)

2. J. Storey, P. M. Wright, D. Ulrich. Strategic Human Resource Management: A Research Overview. London: Routledge. ISBN: 9780429490217 (2019)

3. S. A. Alghamdi. The Impact of HRM strategy on Organizational Effectiveness. American Journal of Theoretical and Applied Business. 6(4), 91-97 (2020)

4. S. Hillebrecht. Die Personalstrategie und Personalplanung des Unternehmens, in: Perspektivenorientierte Personalwirtschaft. Wiesbaden: Springer Fachmedien Wiesbaden. ISBN: 9783658320935 (2020)

5. F. R. David. Strategic Management: A Competitive Advantage Approach, Concepts \& Cases. $15^{\text {th }}$ Ed. New Jersey: Prentice Hall. ISBN: 9780133444797 (2019)

6. P. Boxall. HRM strategy and competitive advantage in the service sector. Human Resource Management Journal. 13(3), 5-20 (2003)

7. C. Chadwick, C. Flinchbaugh. Searching for competitive advantage in the HRM-firm performance relationship. Academy of Management Perspectives. 35(2) (2021)

8. C. Sheehan, H. De Cieri, B. Cooper, T. Shea. Strategic implications of HR role management in a dynamic environment. Personnel Review. 45(2), 353-373 (2016)

9. N. K. Denzin, Y. S. Lincoln. The Sage handbook of qualitative research. $4^{\text {th }}$ ed. Thousand Oaks: Sage Publications. ISBN: $9781412974172(2012)$

10. A. Trost. Neue Personalstrategien zwischen Stabilität und Agilität. Wiesbaden: Springer Fachmedien Wiesbaden. ISBN: 9783662574072 (2018) 
11. E. Knezović, S. Bušatlić, O. Riđić. Strategic human resource management in small and medium enterprises. International Journal of Human Resources Development and Management. 20(2), 114-139 (2020)

12. T. Bagga, S. Srivastava. SHRM: alignment of HR function with business strategy. Strategic HR Review. 13(4,5) (2014)

13. L. Kempová. The Creating of HR Strategy and its Implementation to Organization XYZ. Acta academica karviniensia. 3(2), 33-41 doi:10.25142/aak.2013.022 (2013)

14. E. Lawler, J. Boudreau. Effective HR Management: A Global Analysis, Stanford: Stanford University Press. ISBN: 9780804776875 (2012)

15. J. Urban. Jak propojit personální strategii s celkovou strategií podniku. Práce a mzda. (2020)

16. J. Urban. 40 manažerských mýtů. Praha: Grada Publishing a. s. ISBN: 9788027105717 (2018)

17. A. Trost. Die Entwicklung einer Personalstrategie. Wiesbaden: Springer Fachmedien Wiesbaden. doi:10.1007/9783-662-57407-2_3 (2018)

18. J. E. Delery, D. Roumpi. Strategic human resource management, human capital and competitive advantage: is the field going in circles? Human Resource Management Journal. 27(1), 1-21 doi:org/10.1111/1748-8583.12137 (2017)

19. A. Upamali, J. Weerawardena, M.-L. Verreynne. Learning capabilities, human resource management innovation and competitive advantage. The International Journal of Human Resource Management. 29(10), 1736-1766 (2018)

20. P. Wright, A. J. Nyberg, R. E. Ployhart. A research revolution in SHRM: New challenges and new research directions. Research in personnel and human resources management. 36, 141-161 (2018)

21. M. Brussel, S. Stella. Praxishandbuch Personalmanagement für Handwerksunternehmen. Wiesbaden: Springer Fachmedien Wiesbaden. ISBN: 3662583151 (2019) 